\title{
Contribuição do patologista cirúrgico para o diagnóstico das síndromes do câncer hereditário e avaliação dos tratamentos cirúrgicos profiláticos
}

\author{
Hereditary cancer syndrome: pathologists contribution for diagnosis and evaluation of prophylactic surgical \\ procedures
}

\section{Marcelo Alvarenga ${ }^{1}$ \\ Ana Cristina Cotta ${ }^{2}$ \\ Rozany Mucha Dufloth ${ }^{3}$ \\ Fernando Carlos de Lander Schmitt ${ }^{4}$}

\section{unitermos resumo}

Câncer hereditário

Câncer familiar

Patologia

Neoplasias

Cirurgia profilática
Introdução: As neoplasias malignas em vários órgãos podem apresentar ocorrência esporádica

ou familiar. O patologista cirúrgico desempenha papel decisivo no diagnóstico do câncer

hereditário. Este estudo visou à revisão dos recursos disponíveis na rotina diagnóstica para a

detecção do câncer hereditário, bem como à discussão das abordagens terapêuticas cirúrgicas

profiláticas relatadas. Métodos: Revisão de artigos relacionados às síndromes do câncer

hereditário quanto ao diagnóstico e às cirurgias profiláticas. Resultados: Os principais achados

clínicos indicadores da síndrome do câncer hereditário relatados são: idade precoce ao

diagnóstico, múltiplos tumores primários, vários membros acometidos de uma mesma família e

diversas gerações acometidas. Os tipos histológicos mais freqüentemente associados às

síndromes de câncer familiar são: carcinoma ductal pouco diferenciado e carcinoma medular

da mama, adenocarcinomas serosos de alto grau do ovário, carcinoma medular da tireóide e

carcinoma gástrico difuso. Mastectomia bilateral, ooforectomia bilateral, gastrectomia total e

tireoidectomia total são modalidades de cirurgias profiláticas relatadas. Conclusão: O material

de rotina diagnóstica em patologia cirúrgica fornece informações valiosas para o diagnóstico do

câncer hereditário, podendo influenciar favoravelmente o prognóstico com indicações

apropriadas para rastreamento clínico. A indicação para cirurgias profiláticas permanece

controversa, principalmente quanto às ooforectomias e às mastectomias bilaterais.

\section{abstract}

Introduction: Malignant neoplasia may be sporadic or familial in diverse organs. Pathologists play an important role in the diagnosis of familial cancer syndromes. The aim of this study was to review

diagnostic tools available to surgical pathologists as well as to discuss surgical prophylactic procedures. Methods: M edline search for articles related to hereditary or familial cancer or neoplasia and prophylactic surgery. Results: The most frequent clinical clues for familial syndrome diagnosis are: early age of onset, multiple primary cancers, multiple family members affected by the same or related cancers and multiple affected generations. Histologic types most frequently associated with

familial cancers are: ductal carcinoma with high nuclear grade and medullary carcinoma of the breast, high grade serous carcinoma of the ovary, medullary carcinoma of the thyroid and diffuse gastric carcinoma. Prophylactic surgery in asymptomatic individuals from syndromic families include

bilateral mastectomy, bilateral oophorectomy, total gastrectomy and total thyroidectomy.

Conclusion: Surgical pathologists may contribute to the diagnosis of familial cancer syndrome on daily practice improving patients and relatives prognosis through appropriate surveillance and follow-up. Prophylactic surgery indication criteria remain controversial specially for oophorectomy and bilateral mastectomy. key words

Hereditary cancer

Familial cancer

Pathology

Neoplasia

Prophylactic surgery
1. Professor doutor do Departamento de

Tocoginecologia da Universidade Estadual de Campinas (Unicamp); chefe do Laboratório de Patologia Experimental e Imunoistoquímica do Centro de Atenção Integra à Saúde da Mulher (Caism): médico citopatologista do Instituto de Patologia de Campinas (IPC). 2. Médica patologista do Laboratório de Citopatologia do Caism/Unicamp; aluna do curso de pós-graduação em Ciências Médicas, área de Anatomia Patológica, da Faculdade de Ciências Médicas da Unicamp

3. Médica patologista do Laboratório de Citopatologia do Caism/Unicamp; aluna do curso de pós-graduação em

Tocoginecologia da Faculdade de Ciências Médicas da Unicamp.

4. Professor da Faculdade de Medicina da Universidade do Porto; investigador sênior do Instituto de Patologia e Imunologia Molecular da Universidade do Porto (Ipatimup)

Trabalho desenvolvido durante realização de atividades da disciplina Tópicos em Tocoginecologia do curso de pósgraduação da Faculdade de Ciências Médicas da Unicamp. 


\section{Introdução}

Recentes avanços na biotecnologia e na informática possibilitaram a expansão dos conhecimentos relativos ao diagnóstico e ao estudo das doenças genéticas. A publicação dos resultados preliminares do seqüenciamento inicial e análise do genoma humano em 2001 deu novo impulso às pesquisas genéticas. Entre os responsáveis por doenças genéticas incluídos na lista do seqüenciamento inicial estão o gene de susceptibilidade para o câncer de mama (BRCA2) e o gene associado ao complexo de Carney (PRKAR1A) (40).

As neoplasias podem ser consideradas doenças caracterizadas por instabilidade genética, e ao contrário das síndromes genéticas, em que uma única mutação pode ser suficiente para a determinação de um fenótipo alterado, necessitam do acúmulo de vários danos ao genoma para seu desenvolvimento.

Apenas uma pequena parcela dos cânceres relatados pode ser considerada parte de uma síndrome de câncer hereditário (54). A maior parte resulta de defeitos na replicação do DNA, em seus mecanismos de controle ou pela ação de agentes carcinógenos. Apesar disso, a revisão da literatura em base de dados PubMed com os termos câncer hereditário ou familiar (hereditary ou familial cancer ou neoplasia) relativa ao período de meados da década de 1970 até novembro de 2001 gerou uma listagem de 1.336 .573 artigos.

A investigação teve por objetivo relacionar os aspectos clínicos e morfológicos mais relevantes para o diagnóstico disponíveis para o patologista cirúrgico na rotina, bem como o papel das cirurgias profiláticas na abordagem de pacientes assintomáticos pertencentes a famílias sindrômicas.

\section{Síndrome do câncer hereditánio}

As síndromes são definidas como combinações de sinais e sintomas formando apresentação clínica distinta indicativa de anormalidade particular. As síndromes de câncer hereditário são afecções genéticas nas quais neoplasias malignas parecem se aglomerar em certas famílias. As primeiras descrições de uma síndrome de câncer hereditário remontam ao início do século XX, com a descrição, por Warthin, de uma família acometida por vários casos de neoplasias malignas no cólon, no útero, no estômago e em outros órgãos. Posteriormente passou a ser conhecida como síndrome de Lynch (54) (Quadro 1).
Características clínicas associadas

\section{Quadro 1 ao câncer hereditário}

- Idade precoce ao diagnóstico

- Múltiplas neoplasias em um mesmo indivíduo

- Múltiplos membros de uma mesma família apresentando a mesma neoplasia ou neoplasias relacionadas

- Múltiplas gerações acometidas

Modificado de: Niedorf, 2001 (54); Schmitt, 2001 (63).

Os genes associados às síndromes de câncer hereditário tendem a pertencer mais freqüentemente ou ao grupo dos genes supressores de tumores, que, quando alterados, não desempenham adequadamente seu papel regulador no crescimento celular, ou ao grupo de genes reparadores de erros no DNA. Mais raramente, as síndromes estão relacionadas a oncogenes associados ao câncer quando inadequadamente ativados.

\section{Síndrome do câncer mamário hereditário}

Cerca de $5 \%$ a $20 \%$ das mulheres com neoplasia de mama possuem história familiar, e um quarto herda anomalias cromossômicas autossômicas dominantes, principalmente mutações (1, 41). Em 1990, Hall et al. (31) evidenciaram mutações em células germinativas de um gene no lócus 17q12-21, denominado BRCA1. Estudos posteriores mostraram associação com neoplasia de mama e de ovário (19). Um segundo lócus foi identificado no braço longo do cromossomo 13q12-q13 e denominado BRCA2 (76).

No que tange à neoplasia mamária, o patologista vêse diante, cada vez mais, de fragmentos menores, necessitando treinamento, conhecimento atualizado e experiência.

\section{Definições e conceitos}

As lesões epiteliais da mama a serem observadas pelo patologista na rotina diagnóstica são as hiperplasias ductais típica e atípica, o carcinoma intraductal e o carcinoma invasor. Entre os carcinomas invasores, o mais freqüente é o carcinoma ductal (constituindo $65 \%$ a $80 \%$ dos casos). Os menos freqüentes são o tubular, o medular, o mucinoso, entre outros.

Neste estudo, deter-nos-emos mais no carcinoma ductal invasivo e nos carcinomas medulares típico e atípico 
por estarem mais relacionados à neoplasia mamária hereditária $(2,9)$. Nesse sentido, a avaliação microscópica criteriosa requer conhecimento histopatológico da graduação de Bloom \& Richardson (1957) para o carcinoma ductal invasivo, em face de sua boa reprodutibilidade diagnóstica (24). Obtém-se o grau final do tumor somando-se os pontos da formação tubular, do pleomorfismo nuclear e do índice mitótico (21).

No carcinoma medular típico, observa-se evidente delimitação macroscópica do tumor, proeminente reação linfoplasmocitária do estroma, crescimento em padrão sincicial das células epiteliais, grau nuclear 3 (alto grau) e grande número de mitoses. Na ausência de um destes componentes, trata-se de carcinoma medular atípico.

Solidificados os critérios morfológicos para o diagnóstico dos principais tipos histológicos, o patologista necessita ter conhecimento da literatura vigente para orientar a condução do caso.

Os estudos epidemiológicos mostram vários fatores de risco para o desenvolvimento dessa neoplasia, salientando a história familiar. Estudos do tipo caso-controle evidenciaram risco relativo de duas a quatro vezes nas muIheres com um ou mais parentes de primeiro grau que desenvolveram a neoplasia (57), ocorrendo um aumento progressivo do risco com o aumento do número de familiares afetados (17).Um estudo de caso-controle da população de Utah sobre a história familiar e o risco de desenvolver câncer de mama evidenciou que mesmo o terceiro grau de parentesco de mulher com câncer de mama tem influência adversa no risco de desenvolver a neoplasia (65).
Mulheres com câncer de mama contralateral desenvolvido até três anos do diagnóstico inicial mais comumente poderão ter familiares com câncer (65).

Mulheres que apresentam história familiar possivelmente carregam um componente genético e ambiental no desenvolvimento da neoplasia. Pesquisas de genética molecular evidenciaram que mulheres com mutações do BRCA1 e do BRCA2 possuem características clínicas e familiares distintas, as quais podem ser utilizadas para selecionar os indivíduos que se beneficiariam de um teste molecular para pesquisa de mutações nestes genes $(1,9$, 46, 49) (Quadro 2).

O BRCA1 é um gene supressor tumoral localizado no braço longo do cromossomo 17, constituído por mais de $80 \mathrm{~kb}$, distribuídos em 22 éxons (52). Este gene codifica uma proteína de 1.863 aminoácidos com peso molecular de $220 \mathrm{kd}$, a qual se localiza no núcleo de forma fosforilada; apresenta dois domínios: um domínio em anel (ring), próximo ao $\mathrm{N}$-terminal (6), e um domínio BRCT, próximo ao C-terminal (7). Foram descritas mais de 600 mutações do BRCA1; destas, grande parte é do tipo frameshift, resultando em uma proteína truncada ou inativa.

As mulheres com mutações do BRCA1 apresentam $87 \%$ de chance de desenvolver carcinoma de mama e $40 \%$ a $60 \%$ de chance de desenvolver um carcinoma de ovário durante toda a vida. Ainda, $65 \%$ de chance de desenvolver um segundo carcinoma mamário se viverem até 70 anos $(1,22,57)$.

O BRCA2 é um gene supressor tumoral localizado no lócus $13 q 12$, constituído por 10,4kb dispostas em 27 éxons que codificam uma proteína de 3.418 aminoácidos que se

\section{Quadro 2 Principais características da síndrome do câncer mamário hereditário e de síndromes associadas}

- Herança: autossômica dominante

- Genes: BRCA1 (17q21) e BRCA2 (13q12)

- Mulheres: início antes dos 45 anos de idade, carcinomas bilaterais e associações com neoplasias de ovário, cólon e pâncreas

- Homens: neoplasias de próstata e mama

- Síndrome de Li-Fraumeni

- Síndrome de Cowden

- Síndrome da ataxia-telangiectasia

- Síndrome de Muir-Torre

- Síndrome de Peutz-J eghers

- Síndrome de Reifenstein 
encontra no núcleo da célula em uma forma fosforilada (4). Foram referidas 450 mutações deste gene. As mais freqüentes são as do tipo frameshift e nonsense, que produzem proteínas truncadas ou inativas (69).

As mulheres que apresentam mutação do BRCA2 possuem cerca de $85 \%$ de chance de desenvolverem um carcinoma de mama durante sua vida $(1,10,57)$.

Vários estudos têm sido realizados no sentido de descobrir quais características histológicas estariam presentes no carcinoma de mama hereditário.

Dessas pesquisas, merece destaque o estudo publicado pelo Breast Linkage Consortium (9), que relacionou as características histológicas dos carcinomas hereditários de mulheres com mutações do BRCA1 e do BRCA2, comparando-as às mulheres com carcinoma de mama esporádico. Quando presentes as mutações do BRCA1, o exame histopatológico do espécime cirúrgico revelou maior grau nuclear, menor formação de túbulos, atividade mitótica elevada, infiltrado linfóide exuberante e margens expansivas. Quando presentes as mutações do BRCA2, observam-se margens expansivas, menor formação de túbulos e baixa atividade mitótica (Tabela).

O perfil imunoistoquímico dos receptores hormonais quando associados às mutações do BRCA1 e do BRCA2 revela-se, na grande maioria, negativo para receptor de estrógeno e progesterona, variando de $60 \%$ a $90 \%$ dos casos $(45,66,71)$. Analisando a idade das mulheres com carcinoma de mama hereditário, Lidereau et al. (41) observaram que mulheres na faixa etária de 35 anos com diagnóstico de carcinoma de mama, grau histológico 3 e receptor de estrógeno negativo apresentavam mutações do BRCA1 em $66 \%$ dos casos.

Em resumo, se o patologista estiver diante de um caso de carcinoma de mama em paciente jovem, com grau nuclear elevado, pouca formação de túbulos, grande atividade mitótica e receptor de estrógeno negativo, esse tumor pode estar relacionado a mutações do BRCA1. Quando houver menor formação de túbulos e menor atividade mitótica, possivelmente será um caso associado a mutações do BRCA2. Recentemente, Schmitt et al. (63) demonstraram que a associação entre grau histológico 3, receptor de estrógeno negativo e c-erb-B2 negativo é significantemente mais freqüente nos carcinomas de mama hereditários do que nos esporádicos. Futuros estudos das características anatomopatológicas do carcinoma de mama hereditário contribuirão para a melhor associação destas com os distúrbios genéticos, contribuindo para a redução dos custos e melhor acurácia no manejo clínico das famílias de mulheres com neoplasia de mama.

\section{Tabela Achados clínicos e histopatológicos característicos nos carcinomas hereditários da mama}

\begin{tabular}{lcc}
\hline Característica & BRCA1 & BRCA2 \\
Risco de câncer de mama & $85 \%-87 \%$ & $45 \%-85 \%$ \\
Risco de câncer de ovário & $40 \%-85 \%$ & $15 \%-20 \%$ \\
Risco de segundo câncer de mama & $65 \%$ & - \\
Formação de túbulos & Menor & Menor \\
Pleomorfismo & Maior & - \\
Índice mitótico & Maior & Menor \\
Margens expansivas & Maior proporção & Maior proporção \\
Infiltrado linfóide peritumoral & Proeminente & - \\
Componente de carcinoma in situ & Ausente/ escasso & Ausente/ escasso \\
Receptor de estrógeno & Negativo & Variável \\
Proliferação celular (MIB-1) & Maior & Variável \\
Angiogênese & Maior & Variável \\
TP53 & Maior & Variável \\
c-erb-B2 & Negativo & Negativo \\
Aneuploidia & Mais freqüente & Variável \\
\hline
\end{tabular}

Risco de acumulado de câncer de mama e ovário em 70 anos.

Fontes: Andersen, 1996 (1); Ellisen, 1998 (22); Pharoah, 1997 (57); Schmitt, 2001 (63); Zweemer, 1998 (77). 


\section{Mastectomia profilática}

A mastectomia profilática tem sido considerada a abordagem terapêutica para reduzir os riscos de câncer de mama (20).

Um artigo de revisão recentemente publicado sugere mastectomia bilateral profilática em pacientes com mutações do BRCA1 e do BRCA2 por reduzir os riscos dessa neoplasia, embora sugira que sejam necessários estudos clínicos prospectivos. Recomenda, ainda, mudanças no estilo de vida, com base em estudos pré-clínicos (pesquisa básica) e observacionais (16).

Meijers et al. (51) realizaram um estudo prospectivo em 139 mulheres com mutação BRCA1 e BRCA2. Destas mulheres, 76 que optaram por se submeter a mastectomia profilática bilateral tiveram redução da incidência em três anos de seguimento, quando comparadas ao grupo não- submetido à cirurgia.

\section{Síndrome do câncer ovariano hereditário}

Aproximadamente $5 \%$ a $10 \%$ das mulheres com câncer ovariano apresentam padrão familiar da neoplasia e cerca de $3 \%$ são portadoras de mutações no gene de susceptibilidade ao câncer de mama/ovário BRCA1 $(59,62)$. No grupo de pacientes com história familiar para câncer de ovário, as mutações para o gene BRCA1 podem variar de $30 \%$ a $48 \%$ em grupos selecionados, como as pacientes judias Ashkenazi $(8,74)$ (Quadro 3).

A média de idade, ao diagnóstico, do câncer ovariano hereditário varia entre 42,7 anos e 48 anos nos diversos estudos $(62,77)$, enquanto a média para os casos esporádicos aproxima-se de 61 anos (77). No estudo de 88 pacientes judias Ashkenazi apresentando mutações para os genes BRCA1 e BRCA2, os carcinomas ovarianos foram muito raramente diagnosticados antes dos 40 anos de idade (8). O mesmo estudo detectou diferença estatisticamente significante entre a média de idade ao diagnóstico para mutações do BRCA1, 54 anos, e para o BRCA2, 62 $\operatorname{anos}(8)$.

O câncer ovariano familiar tem sido associado a três síndromes: câncer de mama hereditário sítio-específico, câncer hereditário mama/ovário e câncer hereditário ovariano sítio-específico. Esta divisão, entretanto, tem sido questionada devido à ocorrência ocasional de neoplasias de mama e ovário em pacientes de famílias portadoras de câncer ovariano sítio-específico (77).

\section{Quadro 3 Principais características do câncer ovariano hereditário e principais síndromes associadas}

- Herança: autossômica dominante com penetrância variável

- Genes: BRCA1, BRCA2

- Associações mais freqüentes: mãe/ filha e irmã/ irmã

- Associado a carcinoma ductal de mama sincrônico ou metacrônico (18\%), adenocarcinoma colônico não-polipóide e adenocarcinomas de endométrio

- Inversamente associado ao uso de contraceptivos orais

- Síndrome do câncer de mama hereditário sítio-específico

- Síndrome do câncer hereditário mama/ ovário

- Síndrome do câncer hereditário ovariano sítio-específico

- Síndrome de Lynch tipo II

- Tipo histológico

Adenocarcinoma seroso

Tumor seroso borderline

Adenocarcinoma mucinoso

Adenocarcinoma endometrióide

Adenocarcinoma de células claras

Carcinoma indiferenciado

Grau de diferenciação 3
Hereditário

BRCA1 (t)

Mais freqüente

Pode ocorrer

Raro ou ausente

Mais freqüente

Raro ou ausente

Raro ou ausente

Mais freqüente

\section{Hereditário}

BRCA1 (-)

Mais freqüente

Menos freqüente

Menos freqüente

Menos freqüente

Menos freqüente

Variável 
Alguns estudos a respeito das características histopatológicas dos tumores ovarianos em pacientes portadoras de mutações para o gene BRCA1 têm sido publicados com resultados variáveis $(8,62,74,77)$.

Estudos de grupos holandeses incluíram pacientes com carcinoma ovariano e pelo menos uma parente com diagnóstico de câncer mamário ou ovariano. Nesses estudos, não houve diferença estatisticamente significante entre as freqüências dos tipos histológicos em 42 pacientes acometidas por carcinomas ovarianos familiares comparadas a 4.519 pacientes do registro tumoral, incluindo casos esporádicos, embora tenha sido observada menor ocorrência de adenocarcinomas mucinosos (77).

O Registro de Câncer Ovariano Hereditário Gilda Radner norte-americano contém dados de mulheres cadastradas voluntariamente, incluindo pacientes apresentando pelo menos duas parentes de primeiro ou segundo grau com câncer ovariano documentado. Cistadenocarcinoma seroso foi o tipo histológico mais freqüente, constituindo $25,7 \%$ dos casos familiares e $17,4 \%$ do registro global, incluindo casos esporádicos (59). Estudos posteriores do mesmo registro mostraram proporção de $65,2 \%$ dos tumores ovarianos familiares do tipo seroso (58) (Quadro 3).

Essa aparente discrepância de dados pode estar relacionada à classificação da maior parte das neoplasias incluídas no registro populacional como adenocarcinoma papilífero (termo descritivo de padrão arquitetural) ou adenocarcinoma sem outra especificação (58). Provavelmente, parte dos adenocarcinomas serosos foi incluída sob estas designações.

O adenocarcinoma seroso também foi o tipo histológico mais comum nas pacientes com síndrome do câncer ovariano familiar e mutações do gene BRCA1, constituindo $59 \%$ a $68 \%$ dos tumores, comparados $37 \%$ dos tumores, na ausência de mutação detectável. Nenhum caso de adenocarcinoma mucinoso foi detectado em dois estudos com grupos de 65 e 88 pacientes apresentando mutações $(8,74)$.

Observou-se uma maior ocorrência de tumores bem diferenciados (grau 1) entre pacientes sem mutações do gene BRCA1 (18\%) comparadas àquelas com mutações para o mesmo gene $(2 \%)$, bem como um maior número de pacientes em estádio I no grupo BRCA1 negativo comparado ao positivo (74). Isto pode refletir tanto uma tendência à apresentação da neoplasia em forma mais agressiva quando expressa BRCA1 quanto à expressão deste em fases mais avançadas da neoplasia familiar ou início da doença em idade mais precoce em relação à idade em que o diagnóstico é usualmente suspeitado.
Apesar do maior grau histológico dos carcinomas em pacientes portadoras de mutações para BRCA1, um meIhor prognóstico tem sido relatado para essas pacientes, com sobrevida média de 71 meses para pacientes apresentando mutações no gene BRCA1 comparadas a 29 meses para aquelas sem mutações em grupo de controle pareado por idade (62). Este pareamento visou ao isolamento do fator idade, sabidamente conhecido como favorável ao prognóstico. O melhor prognóstico em pacientes apresentando mutações para BRCA1 e BRCA2 foi relatado também por outros autores (8).

Um estudo comparativo entre laudos anatomopatológicos emitidos na rotina diagnóstica em laboratórios de patologia cirúrgica e centros de referência mostrou concordância de 95,3\% (58). Isto reforça a hipótese de que discrepâncias nas porcentagens dos tipos histológicos em estudos anteriores devem-se a mudanças nas classificações vigentes, e não a critérios subjetivos para a classificação dessas neoplasias.

Outros tipos histológicos têm sido mais raramente associados às síndromes de câncer ovariano hereditário. Há relatos esporádicos da ocorrência familiar de carcinomas de pequenas células $(39,42)$ e de disgerminoma ovariano associado a mutações do BRCA1 (75).

\section{Ooforectomia profilática}

O prognóstico das pacientes com diagnóstico de carcinoma ovariano é geralmente reservado. A sobrevida média em cinco anos tem se mantido estável em aproximadamente $40 \%$, a despeito dos avanços nos tratamentos oncológicos observados nas duas últimas décadas (73). Este fato tem sido atribuído à realização do diagnóstico, na maior parte das vezes, em estágios avançados incuráveis. Entretanto a sobrevida para pacientes com diagnóstico precoce, como, por exemplo, por descoberta incidental, é melhor, gerando grande motivação para a detecção da doença em fases iniciais.

Os estudos de imagem para o diagnóstico precoce dessas neoplasias apresentam baixo valor preditivo positivo na população geral, não justificando sua indicação como método de rastreamento. As indicações para ooforectomias profiláticas têm sido amplamente debatidas na literatura e há numerosos estudos retrospectivos relatados e estudos prospectivos em andamento (73).

Autores defensores dessa abordagem alegam que, uma vez estabelecido um modo de transmissão autossômico dominante, o aconselhamento genético para ooforectomia 
profilática na idade apropriada pode reduzir as mortes por carcinoma ovariano nas famílias sindrômicas (58). A ooforectomia profilática em membros assintomáticos heterozigotos de famílias portadoras de mutações para os genes BRCA1 e BRCA2 tem sido adotada em alguns centros desde a década de 1980, com indicações para cirurgia, preferencialmente antes dos 35 anos de idade (73).

A mesma abordagem tem sido contestada por autores que detectaram aumento da incidência dessas neoplasias apenas a partir dos 60 anos de idade, havendo possibilidade de preservação da fertilidade (8). Outro achado controverso a respeito da eficácia desse procedimento refere-se à ocorrência de carcinomas peritoneais histologicamente idênticos aos carcinomas ovarianos após ooforectomias, isto é, doença multifocal $(36,60,73)$, ou seja, o risco de neoplasia ovariana permanece mais alto do que para a população geral mesmo após a ooforectomia bilateral (61).

A privação estrogênica após ooforectomia está associada a maior incidência de doenças coronarianas, osteoporose e atrofia vaginal. Nos casos em que as pacientes são submetidas à reposição estrogênica ainda não houve avaliação quanto ao risco de carcinoma mamário (73).

Um estudo histológico do produto de ooforectomia profilática foi realizado em 50 pacientes assintomáticas, na ausência de imagens ultra-sonográficas suspeitas ou de níveis elevados de CA-125 com história de pelo menos duas familiares com câncer ovariano ou de uma parente com desenvolvimento da neoplasia em idade jovem (43). Entre estas, quatro (12\%) entre 40 e 65 anos de idade apresentaram tumores ovarianos, dos quais apenas um foi suspeitado macroscopicamente. Os tipos histológicos encontrados foram adenocarcinoma seroso pouco diferenciado (duas pacientes), tumor seroso borderline bilateral micropapilífero e tumor seroso borderline unilateral (43).

Outro estudo histológico relativo a 60 pacientes submetidas a ooforectomias profiláticas comparou 33 pacientes submetidas a ooforectomia profilática portadoras de mutações para BRCA1 a 27 sem mutações, mostrando maior formação de micropapilas na superfície ovariana no primeiro grupo (12).

\section{Síndrome do câncer tireoidlano hereditário}

O carcinoma medular da tireóide é classicamente descrito como de ocorrência esporádica ou familiar. Os carcinomas esporádicos constituem aproximadamente $75 \%$ a
$80 \%$ dos casos, geralmente são solitários e acometem indivíduos adultos com média de idade em torno de 45 anos. O diagnóstico usualmente é realizado após a detecção de nódulo tireoideano frio à cintilografia, em alguns casos acompanhado por diarréia ou por síndrome de Cushing. Apenas raramente não é detectado clinicamente, sendo denominado microcarcinoma medular quando inferior a $1 \mathrm{~cm}$ de diâmetro (32).

Os carcinomas familiares, por outro lado, costumam ser diagnosticados em pacientes mais jovens, com média de idade em torno dos 35 anos, são freqüentemente múltiplos e bilaterais e invariavelmente acompanhados por hiperplasia de células $C$ no parênquima residual. Esta pode ser distinguida das hiperplasias reativas por se apresentar como aglomerados de células interfoliculares grandes, citologicamente atípicas, redondas, poligonais ou fusiformes (56). O termo hiperplasia atribuído a essas proliferações de células $C$ tem sido contestado por alguns autores $(33,56)$. Praticamente todos os casos de carcinomas medulares detectados em crianças são familiares e transmitidos por herança autossômica dominante com penetrância praticamente completa. Muitos casos fazem parte da síndrome de neoplasias endócrinas múltiplas do tipo II (MEN tipos II e III) (Quadro 4).

A síndrome MEN do tipo ll é também conhecida como síndrome MEN do tipo IIA ou síndrome de Sipple, caracterizada por hiperplasia de células $\mathrm{C}$, carcinoma medular de tireóide, feocromocitoma e hiperplasia de células principais da paratireóide. O gene para o tipo II foi localizado no lócus 10q11.2. A síndrome MEN do tipo III, também denominada síndrome MEN do tipo IIB ou síndrome de Gorlin, manifesta-se por carcinoma medular da tireóide, feocromocitoma, ganglioneuromas mucosos e anormalidades esqueléticas. O termo carcinoma tireoidiano medular familiar tem sido adotado para famílias apresentando pelo menos quatro casos na ausência de outras neoplasias associadas (32).

Recentemente alguns estudos epidemiológicos e moleculares têm apontado um padrão familiar em carcinomas não-medulares da tireóide. Aproximadamente 5\% a $10 \%$ de todos os carcinomas tireoidianos são hereditários, provavelmente associados a mutações no gene PTEN e no gene supressor tumoral APC, embora estas possam ocorrer também em carcinomas esporádicos $(25,30,53)$. Aproximadamente $5 \%$ dos carcinomas papilíferos da tireóide associados a carcinomas papilíferos renais apresentam alterações no mapeamento gênico para o lócus 1q21 (48). 


\section{Quadro 4 Principais características do câncer tireoidiano hereditário}

- Carcinoma medular tireoidiano

- Herança: autossômica dominante com penetrância quase completa

- Genes: 10q11.2 (MEN do tipo IIA)

- Idade precoce: diagnóstico antes dos 35 anos

- Apresentação clínica: múltiplos nódulos bilaterais

- Manifestações em outros órgãos: feocromocitomas bilaterais, hiperplasia de células principais da paratireóide

- Tipo histológico: carcinoma medular de tireóide associado a hiperplasia de células C

- Indicadores morfológicos: aumento das células sustentaculares (positivas para proteína S-100)

- Pior prognóstico: necrose tumoral, padrão escamoso, presença de células oxifílicas, reatividade para calcitonina inferior a 50\%, ausência de células intermediárias

- Síndromes associadas ao carcinoma medular tireoidiano

- Síndrome MEN do tipo II (IIA) ou síndrome de Sipple

- Síndrome MEN do tipo III (IIB) ou síndrome de Gorlin

- Síndrome do carcinoma tireoidiano medular

- Outros tipos histológicos: carcinoma papilífero de tireóide (5\% dos casos)

Fontes: Eng, 2000 (25); Hemminki, 2000 (32); Malchoff, 2000 (48)

Há relatos esporádicos de microcarcinoma papilífero com padrão de transmissão familiar $(26,44)$ e de carcinomas de células oxifílicas múltiplos e familiares (38). O termo carcinoma papilífero familiar parece inapropriado por englobar diferentes síndromes genéticas com susceptibilidade para seu desenvolvimento, como a síndrome de Cowden e a polipose adenomatosa familiar $(13,25)$.

\section{Achados morfológicos e imunoistoquímicos}

Durante certo tempo, a identificação de células sustentaculares em tumores tireoidianos foi considerada fator a favor do diagnóstico de paraganglioma em detrimento de carcinoma medular da tireóide. Estudos imunoistoquímicos, entretanto, têm revelado a possibilidade de ocorrência dessas células em carcinomas medulares, sendo este achado mais freqüente nos carcinomas medulares familiares em relação aos esporádicos (50). Uma maior atividade proliferativa detectada por imunoistoquímica para PCNA e para MIB-1 tem sido associada ao carcinoma medular familiar $(37,72)$.

Alguns achados citológicos têm sido relacionados aos carcinomas papilíferos associados à polipose adenomatosa familiar como a maior formação de fascículos e formações espiraladas de células fusiformes em configurações papilíferas, foliculares ou sólidas no contexto das características citológicas do carcinoma papilífero (15). Estes achados correspondem às áreas cribriformes e componentes fusocelulares encontrados nos cortes histológicos dos carcinomas papilíferos mais associados a essa síndrome $(13,25,67)$.

Necrose tumoral, diferenciação escamosa, células oxifílicas no tumor e ausência de células intermediárias têm sido associadas a pior prognóstico em pacientes com carcinoma medular da tireóide esporádico e familiar (25), bem como a ausência de reatividade para bcl-2 (72) (Quadro 4).

\section{Tirreoidectomia profilática}

A tireoidectomia profilática tem sido preconizada para membros assintomáticos de famílias portadoras de neoplasias endócrinas múltiplas do tipo II (MEN II) devido à alta penetrância da herança autossômica dominante e ao elevado risco acumulado de desenvolvimento do carcinoma medular estimado em $60 \%$ a $70 \%$ em 70 anos $(18,28)$.

A presença de mutações no protoncogene RET tem sido utilizada para nortear a seleção de pacientes a serem submetidos a tireoidectomias profiláticas (18). Em um estudo envolvendo 75 pacientes entre 14 e 20 anos, clinicamente assintomáticos, apresentando mutações para o protoncogene RET submetidos a tireoidectomia profilática, ao exame histopatológico 46 (61\%) apresentaram carcinoma medular, que foi bilateral em 28 casos. Os níveis de calcitonina não foram capazes de distinguir pacientes com carcinoma medular da tireóide daqueles apresentando apenas hiperplasia de células C (18). 
Grupos de estudo alemães e austríacos têm preconizado tireoidectomia total a partir dos seis anos de idade com linfadenectomia cervical central para pacientes acima de dez anos ou níveis elevados de calcitonina e linfadenectomia bilateral para aqueles acima de 15 anos de idade, calcitonina elevada ou linfonodos suspeitos (18).

\section{Síndrome do câncer gástrico hereditário}

As caderinas formam uma família de moléculas de adesão celular, dependentes do cálcio, relacionadas a várias funções celulares, entre elas a manutenção das conexões intercelulares, o controle da polaridade celular e a morfogênese (70). A caderina epitelial (E-caderina) é um subtipo específico de caderina, presente em células epiteliais, sendo responsável pela sua integridade e organização (55). Distúrbios e mutações desta família de moléculas estão relacionados à origem de tumores de origem epitelial (3).

Evidenciou-se que a E-caderina tem relação com a gênese do adenocarcinoma gástrico do tipo difuso e que a inativação da mutação do gene da E-caderina $(\mathrm{CDH} 1)$ ocorre com freqüência nesse tipo de tumor $(5,11,47,64)$.

A expressão da E-caderina, entretanto, pode variar em função dos sistemas de quantificação e anticorpos utilizados, podendo apresentar uma variação de $17 \%$ a $92 \%$ no carcinoma gástrico (29). Observa-se diminuição da expressão da E-caderina significantemente relacionada à diminuição da sobrevida (29) e sua maior expressão em tumores Borrmann 4.

Utilizando-se a Classificação de Lauren para adenocarcinomas gástricos, o tipo difuso apresentou $50 \%$ de mutação somática para o gene E-caderina, resultando na destruição dos sítios das pontes de cálcio e perda da expressão da proteína E-caderina (14).

Em resumo, a diminuição da expressão da E-caderina relaciona-se com um pior prognóstico, podendo este marcador ser utilizado na estimativa da sobrevida destes pacientes, embora futuros estudos ainda sejam necessários.

\section{Gastrectomia profilática}

Hoje têm sido postulados testes diagnósticos preditivos em famílias com câncer gástrico e mutações da caderina 1 (CDH1). Há relato do estudo do espécime cirúrgico de cinco pessoas de duas famílias com susceptibilidade para desenvolver câncer gástrico submetidas a gastrectomia profilática.
Macroscopicamente, esses estômagos não apresentavam alterações, porém, após processamento histológico de mais de 200 blocos, evidenciaram-se pequenos infiltrados de células em anel de sinete em pequenos agrupamentos, focalmente, na lâmina própria. Este estudo sugere gastrectomia profilática, principalmente em indivíduos jovens, de famílias com alta penetrância de mutações (35).

\section{Conclusão}

Os fatores mais sugestivos da síndrome do câncer hereditário mamário associado a mutações do BRCA1 são: idade mais jovem ao diagnóstico, grau nuclear elevado, pouca formação de túbulos, grande atividade mitótica e receptor de estrógeno negativo. Quando houver menor formação de túbulos e menor atividade mitótica, possivelmente será um caso associado a mutações do BRCA2.

O câncer ovariano hereditário representa aproximadamente $5 \%$ a $10 \%$ dos cânceres neste sítio e aproximadamente $3 \%$ das pacientes portadoras desta neoplasia apresentam mutações no gene BRCA1 $(59,68)$. Apenas um terço das pacientes de famílias acometidas pela síndrome do câncer ovariano familiar apresentam mutações detectáveis no mesmo gene (74). Este fato demonstra a existência de outros fatores envolvidos no desenvolvimento da neoplasia familiar que necessitam investigação.

Os achados histológicos mais associados ao câncer ovariano hereditário são tipo histológico seroso e alto grau histológico.

À semelhança do carcinoma hereditário mamário, o câncer ovariano hereditário apresenta-se mais freqüentemente como neoplasia pouco diferenciada.

O material de rotina diagnóstica em patologia cirúrgica fornece informações valiosas para o diagnóstico do câncer hereditário. Estas podem direcionar a investigação clínica para os órgãos mais freqüentemente acometidos, influenciando favoravelmente o prognóstico dos pacientes e de seus familiares.

A eficácia dos procedimentos cirúrgicos profiláticos em membros assintomáticos de famílias sindrômicas é a opinião vigente na literatura com relação à síndrome do câncer hereditário tireoidiano, justificando-se pela alta penetrância detectável através do protoncogene RET em transmissão autossômica dominante. Há provável benefício em avaliações preliminares da síndrome do câncer gástrico hereditário. Estudos prospectivos em vários centros serão necessários para avaliar os benefícios da mastectomia e ooforectomia bilaterais profiláticas. 


\section{Referências}

1. Andersen, T.I. Genetic heterogeneity in breast cancer susceptibility. Acta Oncologica, 35(4): 407-10, 1996.

2. Armes, J.E. et al. D istinct molecular pathogeneses of early-onset breast cancers in BRCA 1 and BRCA2 carriers: a population-based study. Cancer Res., 59:2011-7, 1999.

3. Becker, K.F. et al. E-cadherin gene mutations provide clues to diffuse type gastric carcinoma. Cancer Res., 54: 3845-52, 1994.

4. Ber twistle, D. et al. N uclear lo cation and cell cycle regulation of the BRCA 2 protein. Cancer Res., 57:5485-8, 1997.

5. Berx, G et al. D ysregulation of the E-cadherin/catenin complex by irreversible mutations in human carcinomas. Cell Adhes Commun, 6: 171-84, 1998.

6. Bo ddy, M .N . et al.The p53-associated protein MD M 2 contains a new ly characterized zinc-binding domain called the RIN G finger. Trends Biochem Sci, 19: 198-9, 1994.

7. Bork, P. et al. A superfamily of conserved domains in DNA damage-responsive cell cycle checkpoint proteins. FASEB J., 11:68-76, 1997

8. Boyd, J. et al. Clinico pathological features of BRCA-linked and sporadic ovarian cancer. N . Engl. J. M ed., 283(17): 2260-5, 2000.

9. Breast $C$ ancer Linkage C onsortium. Pathology of familial breast cancer: difference between breast cancers in carriers of BRCA 1 or BRC A2 mutations and sporadic cases. Lancet, 349: 1505-10, 1997.

10. Brody, L. \& Biesecker, B. Breast cancer susceptibility genes, BRCA 1 and BRC A2. M edicine, 77: 208-26, 1998.

11. Bukholm, I.K. et al. Expression of E-cadherin and its relation to the $\mathrm{p53}$ protein status in human breast carcino mas. Virchows Arch., 431:317-21, 1997.

12. Casey, M.J. et al. Histology of prophylactic removed ovaries from BRC $A 1$ and BRC A2 mutation carriers compared with noncarriers in hereditary breast ovarian cancer syndrome kindreds. Gynecol. Oncol., 78: 278-87, 2000.

13. Cetta, F. et al. Thyroid carcinoma associated with familial adenomatous polyposis. H istopathology, 31:231-6, 1997.

14. C han, J.K.C. \& W ong, C.S.C . Loss of E-Cadherin is the fundamental defect in diffuse-type gastric carcinoma and infiltrating lobular carcino ma of the breast. Adv.Anat. Pathol., 8(3): 165-72, 2001.

15.Chong,J.M. et al. Aspiration and imprint cytopathology of thyro id carcinoma associated with familial adenomatous polyposis. Diagn. Cytopathol., 23(2): 101-5, 2000.

16. Chlebowski,R.T.Primary care:Reducing the risk of breast cancer. N. Engl. J. M ed. 343(3): 191-8, 2000.

17. C olditz, G .A . et al. Family history, age, and risk of breast cancer. JAM A, 270: 338-43, 1993

18. D ralle, $\mathrm{H}$. et al. Prophylactic thyroidectomy in 74 children and adolescents with hereditary medullary thyroid carcinoma: German and A ustrian experience. W orld J.Surg., 22 (7): 77451,1998

19. Easton, D.F. et al. G enetic linkage analysis in familial breast and ovarian cancer :results from 214 families.Am.J. H um. Genet., 52: 678-701, 1993.
20. Eisen, A . et al. Prophylactic surgery in women with hereditary predispositon to breast and ovarian cancer. J. Clin. Oncol., 18: $1980-95,2000$

21. Ellis, I.O \& Elston,C.W .Tumors of the breast. In: Fletcher, C .D.M Diagnostic histopathology of tumors. Hong Kong: ChurchillLivingstone, 1: 635-89, 1995.

22. Ellisen, L. \& H aber, D. Hereditary breast cancer. Ann. Rev. M ed., 49: 425-36, 1998.

23. Elston, C.W. Grading of invasive carcinoma of the breast. In: Page, D.L. \& Anderson,T.J. (eds.). Diagnostic histopathology of the breast. Edinburgh: C hurchill-Livingstone, 1987, p. 300-11.

24. Elston, C.W. \& Ellis, I.O . Assessment of histologic grade. In: Elston, C.W .\& Ellis, I.O (eds.). Systemic pathology. London: Churchill-Livingstone, 2000, p. 365-84

25. Eng, C \& \& Cancer Research Campaign Human C ancer Genetics Research Group. Familial papillary thyroid cancer: Many syndromes, to o many genes? [editorial] ]. Clin. Endocrinol. M etab., 85(5): 1755-7, 2000.

26. Fernández-Real, J.M. \& Ricart, W . Familial papillary thyroid microcarcinoma. Lancet, 353: 1973-4, 1999.

27. Franc, B. et al. Medullary thyroid carcinoma: Search for histological predictors of survival (1.009 proband cases analysis). H um. Pathol., 29(10): 1078-84, 1998.

28. Frohnauer, M.K. \& D ecker, R.A.Update on the MEN 2A c804 RET mutation: Is prophylactic thyroidecto my indicated? Surgery, 128(6): 1052-8, 2000.

29. Gabbert, H.E. et al. Prognostic value of E-cadherin expression in 413 gastric carcinomas. Int. J. Cancer., 69: 184-9, 1996.

30. G imm, 0 . et al. $D$ ifferential nuclear and cyto plasmic expression of PTEN in normal thyroid tissue, and benign and malignant epithelial thyro id tumors. Am.J.Pathol.,156(5):1693-700,2000.

31. Hall, J. et al. Linkage of early onset familial breast cancer to chromosome 17q21. Science, 250: 1684-9, 1990.

32. Hemminki,K.\& D ong, C . Familial relationships in thyroid cancer by histo-pathological type. Int. J. Cancer, 85: 201-5, 2000.

33. Hinze, R. et al. Primary hereditary medullary thyro id carcinoma: C-cell morphology and correlation with preoperative calcitonin levels. Virchows Arch., 433: 203-8, 1998.

34. Hughes, K.S. et al. Prophylactic mastectomy an inherited predispositon to breast cancer.Cancer, 86:2502-16, 1999.

35. H untsman, D.et al. Early gastric cancer in young, asymptomatic carriers of germ-line E-cadherin mutations. N . Engl. J. M ed. 344(25): 1904-9, 2001.

36. Karlan, B.Y. et al. Peritoneal serous papillary carcinoma, a phenotypic variant of familial ovarian cancer: Implications for ovarian cancer screening. Am.J. O bstet. Gynecol., 180(4): 917-28, 1999

37. Katoh, R. et al. G rowth activity in hyperplastic and neoplastic human thyroid determined by an immunohistochemical staining procedure using monoclonal antibo dy MIB-1. Hum. Pathol., 26(2): 139-46, 1995.

38. Katoh, R. et al. Solitary, multiple, and familial oxyphil tumours of the thyroid gland. J. Pathol., 186: 292-9, 1998.

39. Lamovec, J. et al. Familial occurrence of small-cell carcinoma of the ovary. Arch. Pathol. Lab. M ed., 119: 523-7, 1995. 
40. Lander, E.S. et al. Initial sequencing analysis of the human genome. Nature, 409(6822): 860-921, 2001.

41. Lidereau, R. Major improvement in the efficacy of BRCA1 mutation screening using morphoclinical features of breast cancer. Cancer Res., 60:1206-10, 2000.

42. Longy, M. et al. Familial cluster of ovarian small cell carcinoma: a new mendelian entity? J. M ed. Genet., 33: 333-5, 1996.

43. Lu, K.H. et al. O ccult ovarian tumors in women with BRCA1 or BRCA2 mutations undergoing prophylactic o ophorectomy. J. Clin. Oncol., 18(14):2728-32, 2000.

44. Lupoli, G. et al. Familial papillary thyroid microcarcinoma: a new clinical entity. Lancet, 353:637-9, 1999.

45. Lynch, B.. et al. Patho bio lo gic characteristics of hereditary breast cancer. Hum. Pathol., 29:1140-4, 1998.

46. Lynch, H.T. Hereditary and familial cancer. Disponível em: <http://www.aaoc.org.ar/revista/vol4/ hereditary_and_familiar.htm> Acesso em: 15 nov. 2001.

47. Machado, J.C .et al. E-cadherin gene mutations provide a genetic basis for the phenotypic divergence of mixed gastric carcinomas. Lab. Invest., 79: 459-65, 1999.

48. Malchoff, C.D. et al. Papillary thyroid carcinoma associated with papillary renal neoplasia: genetic linkage analysis of a distinct heritable tumor syndrome.J. Clin. Endocrinol.M etab., 85(5): 1758-64, 2000.

49. Marcus, J.N . et al. Hereditary breast cancer: pathobiology, prognosis and BRCA1 and BRCA2 gene linkage. Cancer, 77:697-709, 1996.

50. Matias-Guiu, X. et al. Sustentacular cells occur frequently in the familial form of medullary thyroid carcinoma. J. Pathol., 184:420-3, 1998.

51. Meijers-H eijboer, H. et al. Breast cancer after prophylactic bilateral mastectomy in women with a BRCA1 or BRCA2 mutation. N. Engl. J. M ed., 345(3): 159-64, 2001.

52. Miki, Y. et al. A strong candidate for the breast and ovarian cancer susceptibility gene BRC A 1.Science, 266:66-71,1994.

53. Miyachi, M. et al. Molecular evidence for multicentric development of thyroid carcinomas in patients with familial adenomatous polyposis. Am.J. Pathol., 157(6): 1825-7, 2000.

54.N iedorf,K.B.\& Shannon,K.M.The role of genetic testing and effect on patient care. Arch. Dermatol., 137(11): 1515-9, 2001.

55. 0 hene-Abukwa, Y. \& Pignatelli, M. Adhesion molecules as diagnostic tools in tumor pathology. Int. J. Surg. Pathol., 8: 191-200, 2000.

56. Perry, A et al. Physiolo gic versus neo plastic C - cell hyperplasia of the thyroid. Separation of distinct histologic and biologic entities. Cancer, 77(4): 750-6, 1996.

57. Pharoah, P.D. et al. Family history and the risk of breast cancer: A systematic review and meta-analysis. Int. J. Cancer, 71: 800-9, 1997.

58. Piver, M.S. et al. Comparative study of ovarian cancer histopathology by registry pathologists and referral pathologists: A study by the $\mathrm{G}$ ilda Radner Familial 0 varian Cancer Registry. Gynecol. Oncol., 78: 166-70, 2000.

59. Piver, M.S.et al. Familial ovarian cancer.A report of 658 families from the Gilda Radner Familial 0 varian Cancer Registry 1981-1991. Cancer 71(2): 582-8, 1993.

60. Piver, M.S. et al. Primary peritoneal carcinoma after prophylactic oophorectomy in women with a family history of ovarian cancer. A report of the Gilda Radner Familial O varian Cancer Registry. Cancer, 71(9): 2751-5, 1993.

61. Rebbeck,T.R. Prophylactic oophorectomy in BRCA 1 and BRCA2 mutation carriers. J. Clin. Oncol., 18(21s): 100s-3s, 2000.

62. Rubin, S.C . et al. C linical and pathological features of ovarian cancer in women with germ-line mutations of BRCA1.N. Engl. J. Med., 335(19): 1413-6, 1996.

63. Schmitt, F.C . et al. Patología del cáncer de mama hereditario. Rev. Senología y Patol. Mam., 14(1):29-35, 2001.

64. Shino,Y.et al. Clinicopatholo gic evaluation of immunohistochemical $\mathrm{E}$-cadherin expression in human gastric carcinomas. Cancer, 76(11): 2193-201, 1995.

65. Slattery, M.L. \& Kerber, R.A. A comprehensive evaluation of family history and breast cancer risk:The $U$ tah population database. JAM A, 270: 1563-8,1993.

66. Soares, R. et al. BRCA1 mutation analysis in a Portuguese population with early-onset breast and/or ovarian cancer. Disease M arkers, 15: 93, 1999.

67. So ravia, C . et al. Familial adenomatous polyposis: A ssociated thyroid cancer. A clinical, pathological, and molecular genetics study. Am.J. Pathol., 154(1): 127-35, 1999.

68. Stratton,J.F.et al. Contribution of BRC A 1 mutations to ovarian cancer. N . Engl. J. M ed., 336(16): 1125-30, 1997.

69. Struewing, J.P. The risk of cancer associated with specific mutations of BRCA1 and BRCA2 among A shkenazi Jews. N. Engl. J. Med., 336: 1401-8, 1997.

70. Takeishi, M. Cadherin cell adhesion receptor as a morphogenetic regulator. Science, 251:1451-5, 1991.

71. Verhoog, L.C. et al. Survival in hereditary breast cancer associated with germline mutations of BRC A2.J.Clin. Oncol., 17(11): 3396-402, 1999.

72. Viale, G. et al. Prognostic value of BCl-2 immunoreactivity in medullary thyroid carcinoma. Hum.Pathol,26(9):945-50,1995.

73.W erness, B.A. \& Elatabbakh, G.H . Familial ovarian cancer and early ovarian cancer: Biologic, pathologic, and clinical features. Int. J. Gynecol. Pathol., 20(1): 48-63, 2001.

74.W erness, B.A. et al. Histopathology of familial ovarian tumors in women from families with and without germline BRC $A 1$ mutations. Hum. Pathol. 31(11): 1420-4, 2000.

75.W erness, B.A .et al. Primary ovarian dysgerminoma in a patient with a germline BRCA1 mutation. Int. J. Gynecol. Pathol,, 19(4): 390-4, 2000.

76. W ooster, R. et al. Localization of a breast cancer susceptibility gene, BRCA2, to chromosome 13q12-13. Science, 265: 2088-90, 1994.

77. Zweemer, R.P. et al. Clinical and genetic evaluation of thirty ovarian cancer families. N. Engl.J.M ed.,178(1):85-90,1998

\section{Endereço para correspondência}

Marcelo Alvarenga

Laboratório de Patologia Experimental

Caism/Unicamp

Rua Alexandre Fleming 101

Cidade Universitária Zeferino Vaz - Barão Geraldo

CEP 13083-970 - Campinas-SP 